\title{
POR TODA UMA VIDA FEMINISTA: ENTREVISTA COM JOANA MARIA PEDRO
}

Foi na cidade de Itajaí-SC que nasceu Joana Maria Pedro. Dotada de uma voz agradável e também firme, mulher sem meias palavras, ela nos ensina como devemos apoiar outras mulheres. Sua luta não é recente. Faz parte de sua formação continuada, de suas viagens à Europa, do contato em um ambiente profícuo e intelectual com feministas francesas há pelo menos duas décadas, em suas andanças em eventos acadêmicos, entre outros.

Sua luta perpassa pelos direitos das mulheres - tanto as acadêmicas, políticas, feministas, quanto as donas de casa, invisibilizadas pela História. Autora e organizadora de várias obras que têm contribuído para o campo da história das mulheres, dos estudos de gênero e da teoria feminista, ela é doutora em História Social pela Universidade de São Paulo (USP), com pós-doutorado pela Université d'Avignon et des Pays de Vaucluse. Atualmente, é professora titular em História Social do Departamento de História da Universidade Federal de Santa Catarina (UFSC). Compõe como pesquisadora o Instituto de Estudos de Gênero (IEG/UFSC). É autora de alguns livros publicados, tais como Mulheres honestas, mulheres faladas e Nas tramas entre o público e o privado. Além disso, é co-organizadora dos livros Gênero, feminismos e ditaduras no Cone Sul e Nova História das Mulheres no Brasil. Tem também vários capítulos publicados em diversas coletâneas, como por exemplo: História das mulheres no Brasil, O Brasil no contexto 1987-2007 e História da Cidadania.

Se, algum dia, alguma feminista se entusiasmar em fazer a biografia de Joana, não pode deixar de fora, para além da historiadora, feminista, mãe, professora, orientadora, ativista, companheira, o ser humano solidário e sensível que ela é, e de como nos representa. Somos todas historiadoras, mas com a Joana aprendemos a ser feministas atuantes acadêmica e politicamente em prol dos direitos das mulheres desse país - luta por direitos e oportunidades iguais. A nossa formação em História relegou um papel importante e comprometido com o social no tempo e espaço. E com a Joana Maria Pedro abriu caminho, para as gerações futuras, com um legado para continuar a luta em busca de um mundo possível em que a esperança convirja em uma revolução contra todas as formas 


\section{HISTÓRIA}

Dossiê: Ensino de História, História das Mulheres e Desigualdades Sociais no Brasil de injustiça e de desigualdades de gênero que atravessam o cotidano de milhões de mulheres no Brasil.

É dessa proeminente historiadora feminista que o presente Dossiê História das Mulheres, Gênero e Desigualdades Sociais no Brasil conta com uma entrevista inédita que veio corroborar, inegavelmente, com a potencialidade da obra e suscitar debates inovadores.

Em virtude da pandemia causada pela COVID-19, a professora Joana Maria Pedro concedeu a entrevista por escrito a mim que subescrevo esta apresentação, e as professoras historiadoras Profa. Dra. Kênia Érica Gusmão Medeiros (IFG) e Profa. Ma. Paula Faustino Sampaio (UFR). Em 31 de maio de 2020 recebemos, por correio eletrônico, a presente entrevista - um convite ao diálogo e a um viver feminista.

Gilmária Salviano Ramos

(Prof ${ }^{\mathrm{D}} \mathrm{Dr}^{\mathrm{a}}$. visitante do Dep. de História da UFV)

\section{Eixo 1 - Educação como prática de liberdade}

Entrevistadoras: - Professora Joana Maria Pedro, na abertura do Trigésimo Encontro Nacional da Anpuh, em Recife, em 2019, a senhora fez um discurso político de resistência em que afirmou os estudos de gênero como ferramenta para transformações sociais. Dentre os momentos marcantes dessa fala, destacamos os relatos sobre denúncias de doutrinação contra professores(as) no exercício da docência. Levando em conta o período em que a senhora esteve como presidenta da instituição, e, também, em vista de suas viagens a trabalho dentro e fora do Brasil, como a senhora avalia as condições de trabalho da professora e do professor brasileiros(as)?

Joana Maria Pedro: - A disciplina História e o Ensino de História sempre tiveram muito valor. Fizeram parte da construção da nacionalidade. Construíram uma história comum, disso todas ${ }^{1}$ nós sabemos. Historiadores como Robert Southey,

\footnotetext{
${ }^{1}$ Aviso que irei utilizar o "feminino como universal", até para lembrar que o "masculino universal" da língua portuguesa é uma invenção e exigência datada.
} 
Dossiê: Ensino de História, História das Mulheres e Desigualdades Sociais no Brasil

que escreveu a primeira História do Brasil e a publicou em Londres, na Inglaterra, entre 1810 e 1819, sendo traduzida e publicada no Brasil apenas em 1862, estava contribuindo para a noção de brasilidade, e da mesma forma fizeram historiadores - sempre homens -, como Francisco Adolfo Varnhagen e outros. A história - pensada, na época, como "mestra da vida", sempre foi muito valorizada. Assim como a memória, embora saibamos que não se confunde com ela, a História sempre foi alvo de tentativa de controle. Ficar na história, sair da vida para "entrar na história", deixar um legado para a história, faz parte da longa duração do desejo de permanecer para além da vida. Faz parte do sonho de imortalidade humana, ou seja, continuar viva depois da morte.

O que eu posso observar, então, é a importância que a memória e a história tem para diversos países. É impressionante ver, na Europa Ocidental e nos Estados Unidos, o tratamento dado aos museus e arquivos históricos, o interesse em livros de história e no Ensino de História. Por outro lado, é reconhecida a forma como revoluções de qualquer tipo, assim como governos autoritários, tentam controlar a história que será contada. Querem assegurar-se de que é a sua narrativa do passado que irá prevalecer. Não é por acaso que este governo, que assumiu a presidência em janeiro de 2019, persegue professoras de História, e também a pesquisa em História e, especialmente as discussões de gênero e diversidade na Escola. No caso da História, trata-se de controlar a narrativa que será feita da história do Brasil nas salas de aula. Uma série de declarações de negacionismo tem apontado para isso. Veja-se a negação do golpe militar, em 1964, apelidado de "Revolução", a qual teria impedido o Brasil de se tornar comunista. Negam a tortura, mortes e desaparecimentos, afirmando se tratarem, apenas, de alguns exageros de policiais, e que não seria uma política de governo. Em relação à escravidão, afirmam que esta teria sido útil aos africanos por tê-los civilizado, e que Zumbi não seria um herói, mas bandido, e que se deveria enaltecer os feitos da Princesa Isabel. Lembro que estes negacionismos não são exclusivos do Brasil. Em âmbito internacional, o crescimento da extrema direita tem levado a discussões negacionistas em relação ao holocausto dos judeus nos campos de concentração, pelos nazistas, afirmando que se tratava apenas de campos de prisioneiros; negam as mortes da inquisição; e, ultimamente, negam o massacre realizado pelos colonizadores europeus na 
Dossiê: Ensino de História, História das Mulheres e Desigualdades Sociais no Brasil

América, na África e na Ásia, afirmando que estes trouxeram a civilização para os continentes mencionados.

Em relação a quem pesquisa e ensina História no Brasil, houve, deste o final da ditadura militar, uma grande valorização da pesquisa. As "comissões da verdade", o estímulo às narrativas sobre o período da ditadura, a busca dos movimentos sociais - os mais diversos -, de terem eles, também, uma história, significou muita pesquisa. A questão que se fazia antes de 2016 era: como fazer chegar estas pesquisas aos livros didáticos? Várias comissões de avaliação dos compêndios didáticos passaram, inclusive, a exigir nos manuais a inclusão de histórias que nunca eram contadas. Acompanhamos o crescimento dos recursos para pesquisa e a ampliação de cursos de História, nas novas universidades federais que foram criadas.

O que se vê agora é um grande fechamento. Primeiro a desqualificação de disciplinas das áreas de ciências humanas, em geral, e da História em particular. Chegou-se a dizer que somente eram obrigatórias no Ensino Fundamental, matemática e língua portuguesa. Começaram perseguições. Acompanhei professores de História de diferentes níveis de ensino que passaram a ser processados pelo que disseram, pelo que ensinavam. Muitas vezes eram, somente pais, indo à escola para denunciar junto à direção. Em escolas particulares, essas denúncias significaram a demissão de professores de História. Entre as denúncias havia, por exemplo, falar de ditadura no Brasil, falar de religião africana, falar de escravidão. E, principalmente, claro, falar de gênero e de sexualidade. Neste momento, respondendo diretamente sua pergunta, vejo que ser professora no Brasil tornou-se muito difícil: salários baixos, perseguição por falar de determinados conteúdos em sala de aula e, especialmente, desqualificação da profissão. Por outro lado, não creio que conseguirão manter tudo isso por muito tempo. Há, agora, uma vontade de doutrinação muito forte. Mas, este é um país muito grande. E, neste momento de pandemia, tenho visto mães e pais desesperados com crianças dentro de casa, e se perguntando como professoras conseguem ensinar seus filhos? Talvez estejam aprendendo a valorizar o trabalho de ensinar. 
Dossiê: Ensino de História, História das Mulheres e Desigualdades Sociais no Brasil

Entrevistadoras: - No caso da violência sexual e de gênero, quais são as principais dificuldades que as mulheres têm enfrentado para conquistarem o respeito aos seus corpos e à valorização da vida em uma sociedade misógina e sexista como é a nossa? E, considerando o contexto atual da pandemia da COVID-19, qual sua interpretação acerca dos dados sobre o aumento da violência doméstica?

Joana Maria Pedro: - Quero começar reconhecendo o aumento da violência doméstica com a pandemia do COVID-19. Isso tem sido constatado por pesquisas, dados de denúncias e número de feminicídios. Gostaria de recuperar uma palavra que foi muito comum nos anos setenta e oitenta, para se referir à sociedade que mantém a misoginia, mesmo sendo, esta, tão combatida: "atavismo"2. Esta palavra refere-se à biologia e podemos criticar dizendo que estavam naturalizando; mesmo assim, esta palavra é boa para pensarmos como podem emergir pensamentos, comportamentos desqualificadores das mulheres, que pensávamos terem desaparecido.

Sabemos que esta situação de emergência da misoginação não acontece somente no Brasil; em outros países, a "onda conservadora" tem trazido, em seu bojo, esta forma "atávica" de desqualificar as mulheres. A crise econômica internacional, o desemprego, o empobrecimento que temos visto neste início de século XXI, têm feito emergir grupos políticos que se auto afirmam como machistas e racistas, e não têm vergonha de expor seu preconceito.

A convivência forçada pelo isolamento, junto com crianças, tendo que viver cotidianamente com a diferença e o desemprego, deve estar levando muitos homens a considerar que o único espaço de exercício de mando é a casa, a mulher e os filhos.Vários homens têm reclamado muito da exigência de ficar em casa: afinal, para eles, seu lugar sempre foi o espaço público.

Para as mulheres, a pandemia representa o aumento de trabalho. Filhos em casa, ausência de possíveis auxiliares, como familiares ou mesmo empregadas domésticas, a dificuldade de estabelecer divisão de tarefas no lar, provocada pelo machismo, têm sobrecarregado as mulheres. Em home office as mulheres não deixaram de fazer trabalhos que garantem algum rendimento, e ainda tem

\footnotetext{
${ }^{2}$ Atavismo é o reaparecimento de características, há muito tempo desaparecidas na espécie, produto da evolução. No caso de humanos, seria o reaparecimento de um fenótipo, desaparecido após várias gerações.
} 
Dossiê: Ensino de História, História das Mulheres e Desigualdades Sociais no Brasil

que dar conta de todas as atividades. Todo isso deve estar trazendo muita tensão. Pesquisas têm mostrado que as mulheres acadêmicas não estão produzindo na mesma quantidade que os homens. Uma pesquisa da FAPESP mostrou que apenas $17,4 \%$ dos homens com filhos, e 9,9\%de mulheres com filhos, conseguem prosseguir com a pesquisa e a redação de artigos, na pandemia ${ }^{3}$. Aqui se observa a diferença do impacto.

Outra questão agravada pela pandemia e isolamento social: em épocas comuns, as mulheres podem sair, ir visitar algum familiar ou amiga que Ihes dá apoio, podem procurar ajuda. Isoladas dentro de casa, quem vai lhes dar apoio? Sabemos de casos de mulheres que têm buscado formas as mais diversas de se comunicar e pedir socorro. Acompanhamos recentemente uma jovem que, durante uma vídeo-conferência, justamente sobre violência doméstica, conseguiu se comunicar com as demais pessoas denunciando a violência que acabara de sofrer. Outro caso, que aconteceu em Santa Catarina, uma mulher, vítima de violência doméstica, escreveu um pedido de socorro numa toalha, e a colocou na janela de sua casa. ${ }^{4}$ Vizinhas que têm escutado gritos, têm denunciado as violências na vizinhança. Uma loja acaba de criar um aplicativo de compras que permite fazer denúncias sobre violência doméstica ${ }^{5}$. $O$ aplicativo está conectado ao canal de denúncias do governo federal.

Enfim, a crise econômica e o isolamento social, causados pela pandemia, têm trazido o aumento dos casos de violência contra as mulheres. É preciso encontrar mecanismos para que as mulheres possam denunciar de forma segura, por meio de sites, telefones, etc. E mais precisamos, cada vez mais mostrar que as tarefas domésticas e de cuidado com os filhos, tem que ser partilhadas. Está na hora de entender que a casa é um lugar político, onde

\footnotetext{
${ }^{3}$ Ver: PIERRO, Bruno di. Mães na quarentena. Isolamento social lança luz sobre desigualdade de gênero na ciência. Revista de Pequisa da Fapesp. Disponível em: https://revistapesquisa.fapesp.br/2020/05/19/maes-na-quarentena/ Acesso em: 31 maio 2020. ${ }^{4}$ Ver: MULHER vítima de violência escreve pedido de socorro com batom em toalha e joga pela varanda em SC. G1 - Santa Catarina. Disponível em: https://g1.globo.com/sc/santacatarina/noticia/2020/04/20/mulher-vitima-de-violencia-escreve-pedido-de-socorro-com-batomem-toalha-e-joga-pela-varanda-em-sc.ghtml. Acesso em 29 maio de 2020.

5 Ver: AVERBUCK, Clara, Aplicativo do Magazine Luiza traz botão para denunciar casos de violência doméstica. 292020.2 maio 29 emonível https://revistaforum.com.br/blogs/outravibe/aplicativo-do-magazine-luiza-traz-botao-paradenunciar-casos-de-violencia-domestica/amp/. Acesso em 29 maio 2020.
} 


\section{HISTÓRIA}

Dossiê: Ensino de História, História das Mulheres e Desigualdades Sociais no Brasil relações de poder definem quem vai ficar exausta com as inúmeras responsabilidades.

Entrevistadoras: - Na universidade, percebemos violência de gênero e sexual. Qual a sua opinião acerca do aumento das denúncias de assédio sexual e abuso de poder na universidade? Podemos dizer que, atualmente, discentes têm mais coragem de denunciar as violências?

Joana Maria Pedro: - Sim, eu penso que as jovens de hoje denunciam e que as jovens do passado não denunciavam, escutavam caladas. Gosto de lembrar que minha mãe sempre me ensinou (e a mãe dela fez o mesmo) que "mulher direita não tem ouvido", isso significava que quando uma mulher "direita" ouvia um insulto, um assovio, um gracejo, ou até um elogio, constrangedor, na rua, de um estranho, deveria ignorar e fingir que não ouvia. O mesmo deveria suceder nos locais de trabalho ou de estudos com os colegas. O assédio deveria ser ignorado. A jovem deveria fingir que não recebeu a cantada, e que não foi assediada. E, em caso de abuso de poder, quando alguma autoridade tentava impor seu desejo sobre a jovem, esta deveria se afastar, pedir para trocar de lugar, ir trabalhar em outro setor, se fosse o caso. Em nenhuma hipótese deveria denunciar o assediador. Afinal ela, por ser "direita", não deveria ter "ouvidos". Mas, felizmente, isso mudou. Hoje as jovens denunciam, apontam, reclamam, processam. Consideram que não devem sair de um lugar onde são assediadas. O lugar é que deve ser modificado e o assediador é quem deve desocupar aquele lugar. Fico muito feliz com esta atitude das jovens. É um novo feminismo.

Entrevistadoras: - Em 2015, a presidenta Dilma Roussef, primeira mulher presidenta do Brasil, sofreu o impeachment, além de ter sido vítima de vários adesivos misóginos endossados pela mídia. Tudo isso como efeito de uma sociedade machista e sexista. No seu ponto de vista, quais as principais implicações da diminuta ocupação de mulheres dos governos nos últimos anos?Qual a sua compreensão acerca do posicionamento ideológico antifeminista assumido por mulheres parlamentares e integrantes de governos nos últimos anos? 
Dossiê: Ensino de História, História das Mulheres e Desigualdades Sociais no Brasil

Joana Maria Pedro: - O Brasil, infelizmente, ocupa o 134 lugar, entre 193 países, em relação à presença de mulheres no Parlamento. São 77 mulheres deputadas, de 513 cadeiras na Câmara, e 12 senadoras para um total de 81 vagas no Senado. O atual presidente do poder executivo conta apenas com $9 \%$ de mulheres nos cargos. São 2 mulheres para 22 cargos de ministro. ${ }^{6}$

No Brasil, como em muitos outros países, a participação de mulheres nas eleições encontra várias dificuldades. Vou citar algumas: 1) a forma como as eleições acontecem, com lista aberta; 2) escassos recursos para fazer a campanha; 3) estrutura dos partidos sob dominação masculina; 3) uma cultura misógina que desqualifica as mulheres em lugares de poder; 4) a violência política de gênero. ${ }^{7}$

Tudo isso explica a pouca presença das mulheres em espaços de poder. Sempre é bom lembrar que, no Brasil, as mulheres representam $52 \%$ da população.

O que se pode observar é que, raramente, as meninas e mulheres pensam os lugares no setor público, como um lugar para elas. Mesmo com a política de cotas aprovada em 20\% em 1995 e em 30\% em 1997, nada disso tem sido suficiente. Há um grande rechaço em relação às mulheres que desejam ou que ocupam posições de poder.

O impeachment da Presidenta Dilma mostrou as várias faces desta "violência política de gênero". Claro que o processo não foi feito por ela ser mulher, mas o fato de ela ser uma mulher colaborou muito para sofrer o impeachment. A cultura misógina, o "atavismo" que desqualifica as mulheres no poder, tornaram o processo muito mais ágil. O modo como a imprensa falou da presidenta, as fotos, a escolha das imagens de capas de revistas, apontavam-na como louca, incapaz, incompetente para governar um país, além de alvo de piadas de baixo

\footnotetext{
${ }^{6}$ Ver: CÂMARA DOS DEPUTADOS. Baixa representatividade de brasileiras na políticas se reflete na Câmara. 29 de mar. 2019. Disponível em: https://www.camara.leg.br/noticias/554554-baixarepresentatividade-de-brasileiras-na-politica-se-reflete-na-camara/. Acesso em: 25 maio 2020. ${ }^{7}$ Chama-se violência política de gênero um delito que é feito contra as mulheres; é uma ação na qual uma ou várias pessoas no exercício do poder público pressiona, persegue, hostiliza e ameaça com a finalidade de se apropriar de seu poder, ou induzi-la a tomar decisões contra a sua vontade e seus princípios ético políticos. Sobre isso, ver ALBAINE, Laura. Obstáculos y desafíos de la paridad de género. Violencia política, sistema electoral e interculturalidad. Íconos. Revista de Ciencias Sociales. Num. 52, Quito, mayo 2015, pp. 145-162.
} 


\section{HISTÓRIA}

Dossiê: Ensino de História, História das Mulheres e Desigualdades Sociais no Brasil

calão e imagens altamente desqualificadoras. A este respeito, participei de uma publicação, mostrando algumas destas imagens. ${ }^{8}$

Não podemos dizer que esta desqualificação das mulheres em espaços de poder no setor público seja feita apenas pelos homens. A sociedade é misógina. As mulheres também desqualificam outras mulheres.

Além disso, algumas mulheres utilizam-se do machismo para, ao enfrentar as ideias feministas, ganhar poder. Este poder costuma ser instável; elas mesmas experimentam o machismo - que negavam -, quando assumem cargos no Estado. Temos observado isso acontecer com mulheres do PSL - Partido Social Liberal, eleitas em 2018, as quais ao discordarem do atual governo, em alguma proposição, sofrem intensa violência política de gênero de seus próprios companheiros.

\section{Eixo 2: Feminismos, intersecções e militância de jovens e professoras na escola}

Entrevistadoras: - Professora Joana, o que a senhora poderia apontar como conquistas significativas dos movimentos feministas de Segunda (1970-1980) e de Terceira Ondas (1990) frente à cultura do estupro e do feminicídio no Brasil? Joana Maria Pedro: - Tanto o combate ao estupro como à violência contra mulheres estiveram presentes, tanto na segunda quanto na terceira onda feminista. Podemos dizer que os anos noventa deram novos nomes às antigas lutas. No caso do feminicídio e da violência doméstica, a Terceira Onda conquistou uma legislação.

em 1984, Audre Lorde dizia que ser feminista era dar nomes ao que sentimos, antes de terem nomes. Ela, no texto, fala de racismo e de sexismo ${ }^{9}$, mas eu quero, aqui, fazer uma relação com "cultura do estupro" e o "feminicídio". Estes também são nomes atribuídos a algo que sentimos, que já tiveram outros nomes e que não estão resolvidos. Durante a Segunda Onda no Brasil, a luta contra o

8ZDEBSKY, J. F.; MARANHAO, E. M. A.; PEDRO, Joana Maria. A histérica e as belas, recatadas e do lar: misoginia à Dilma Rousseff na concepção das mulheres como costelas e dos homens como cabeça da política brasileira. Espaço e Cultura (UERJ), v. 38, p. 225-250, 2015.

9 Ver: LORDE, Audre. Sister Outsider: Essaysand Speeches. Crossing Press: Trumansburg. N Y, 1984, p, 152. Apud AHMED, Sara. Vivir una vida feminista. Trad. María Enguix. Barcelona: Edicions Bellaterra, 2018, p. 55. 


\section{HISTÓRIA}

Dossiê: Ensino de História, História das Mulheres e Desigualdades Sociais no Brasil

assédio e o estupro foi intensa, mas não era resumida na noção de "cultura do estupro", que vai aparecer nos debates, nas pesquisas, nas manifestações, nos anos noventa em diante. O mesmo ocorre com a palavra "feminicídio". Na Segunda Onda, a luta para acabar com a violência contra as mulheres se materializou, desde os anos oitenta, em Delegacias da Mulher e, principalmente, com o slogan "Quem ama, não mata", este surgido na campanha contra a absolvição de Doca Street pelo assassinato de Ângela Diniz, ocorrido em 30 de dezembro de $1976 .{ }^{10}$

Podemos então, afirmar que algumas pautas da segunda Onda do feminismo transformaram-se em leis na terceira onda; estes são os casos da Lei Maria da Penha, aprovada em $2006^{11}$, e do Feminicídio, de $2015^{12}$.

Entrevistadoras: - Atualmente, as redes sociais fazem parte da vida de grande parte dos(as) jovens que estão recebendo educação histórica em diferentes níveis e modalidades de ensino. Desse modo, percebemos uma significativa presença da juventude na militância feminista que alguns já caracterizam como a Quarta Onda. Como a senhora vê essa ocupação de lugares de fala no movimento pela juventude atual? A senhora acredita que o ensino de História possa se configurar como possibilidade de abertura de diálogo com esses jovens?

Joana Maria Pedro: - Sim. A Quarta Onda é principalmente jovem, negra e tem atuado no ciberespaço no Brasil. Esta militância é feita na internet e era feita, também, nas ruas, quando a pandemia não tinha restringido as pessoas ao espaço doméstico. Muitas das manifestações nas ruas foram convocadas pelos

\footnotetext{
${ }^{10} \mathrm{~A}$ este respeito, ver o capítulo: LAGE, Lana; NADER, Maria Beatriz. Violência contra a mulher: da legitimação à condenação social. In: PINSKY, Carla B. \& PEDRO, Joana Maria. Nova História das Mulheres no Brasil. São Paulo: Contexto, 2013, p, 297-299.

${ }^{11}$ Sobre Lei Maria da Penha ver: BRASIL. Presidência da República. Casa Civil. Subchefia para Assuntos Jurídicos. Lei no 11.340 de 7 de agosto de 2006. Brasília, 8 ago. 2006. Seção 1, p.1-4. Atualizada por BRASIL. Presidência da República. Lei $n^{\circ} 13.827$, de 13 de maio de 2019. Brasília, Seção 1 - 14 maio 2019, p. 3.

12 Sobre Lei do feminicídio ver: BRASIL. Lei no 13.104, de 09 de março de 2015. Altera o art. 121 do Decreto-Lei $n^{\circ} 2.848$, de 7 de dezembro de 1940 -Código Penal, para prever o feminicídio como circunstância qualificadora do crime de homicídio, e o art. $1^{\circ}$ da Lei $n^{\circ} 8.072$, de 25 de julho de 1990, para incluir o feminicídio no rol dos crimes hediondos. Disponível em: http://www.planalto.gov.br/ccivil 03/ Ato2015-2018/2015/Lei/L13104.htm >. Acesso em 27 maio 2020.
} 
Dossiê: Ensino de História, História das Mulheres e Desigualdades Sociais no Brasil

diferentes meios: facebook, whatsapp, instagram, etc... Acabaram configurando aquilo que foi chamado de "Primavera Feminista".

Toda esta movimentação, e principalmente a de rua, recebeu um grande impulso em 2015, por ocasião da luta contra o projeto Projeto 5.069/13, encaminhado pelo então deputado Eduardo Cunha, que tipificava como crime contra a vida o anúncio de meio abortivo e previa penas específicas para quem induzisse a gestante à prática de aborto. ${ }^{13}$

Para a historiografia, o crescimento da História do Tempo Presente tem buscado dialogar com estes movimentos, estas demandas e estes novos suportes de comunicação e de militância. Mostrar para as jovens como, em diferentes momentos, as formas de luta se configuraram, lidaram com as camadas de tempo, com os diferentes suportes, aproxima a História do cotidiano vivido. Quem pesquisa e ensina história precisa acompanhar e usar as novas tecnologias para tornar a disciplina História um meio de acesso à cidadania.

Entrevistadoras: - A pauta da maternidade e seus desafios, especialmente no mundo do trabalho e na educação formal, tem sido cada vez mais presente nos debates feministas. Sabemos que a luta por creches nos anos 1970 e 1980 foi uma demanda levantada por movimentos feministas, demonstrando, assim, a preocupação do movimento com a situação das mães. Professora, como a senhora avalia os esforços feministas atuais, especialmente nos espaços escolar e acadêmico, sobre as especificidades das estudantes e pesquisadoras que são mães?

Joana Maria Pedro: - Sim, a creche foi uma pauta muito importante do feminismo de Segunda Onda no Brasil. Foi somente na Constituição de 1988 que a educação de crianças de 0 a 3 anos foi definida como dever do Estado. Durante os anos setenta e início dos oitenta, o movimento de mulheres e feministas trouxeram a creche como pauta de emancipação. Nas manifestações, em diferentes espaços, a palavra de ordem era "O filho não é só da mãe", ou seja, a maternidade é de responsabilidade social e não individual. A presença crescente das mulheres no mercado de trabalho, a exigência de arranjos para

\footnotetext{
${ }^{13}$ Ver a este respeito: PEDRO, J. M.; LEMES, L. B. A Primavera das Mulheres nos impasses atuais da democracia no Brasil. In: Joana Maria Pedro; Jair Zandoná. (Org.). Feminismos \& Democracia. 1ed. Belo Horizonte: Fino Traço, 2019, v. 1, p. 67-86.
} 
Dossiê: Ensino de História, História das Mulheres e Desigualdades Sociais no Brasil

saber onde ficariam as crianças, tornaram a creche e a educação pré-escolar (crianças de 4 a 5 anos e 11 meses) uma necessidade. Vários periódicos feministas dos anos setenta e oitenta, como "Brasil Mulher", "Nós Mulheres" e "Mulherio", trouxeram em suas páginas a luta por creches. ${ }^{14}$

Mesmo tendo passado tantos anos, apesar de terem sido criadas inúmeras instituições para atender à educação infantil, e de se notar uma maior participação dos pais no cuidado com as crianças, o que se constata é que a maternidade representa, para as mulheres, um grande impacto em suas carreiras. A este respeito, têm aparecido nas universidades grupos de mães estudantes, feministas, exigindo que a instituição Ihes ofereça apoio. Tanto o CNPq, quanto a CAPES, por exemplo, permitem a prorrogação de bolsas e de prazos das estudantes que engravidaram durante o período que estão na pósgraduação. Várias pesquisadoras têm registrado, no seu Lattes, no resumo do currículo, que foram mães em determinado período, devido ao impacto da maternidade na carreira.

Em âmbito internacional, pesquisadoras feministas têm reivindicado atenção das instituições universitárias e dos órgãos que financiam pesquisa, para a pauta que as feministas da Segunda Onda já reclamavam nos anos setenta: "a maternidade é social" e, como tal, precisa ter suas responsabilidades divididas com a sociedade. Um pesquisador pai, por exemplo, não tem o mesmo impacto, em sua carreira, que uma pesquisadora que se torna mãe.

Buscando reduzir o preconceito e a discriminação de gênero, a AHA - American Historical Association - o correspondente à ANPUH, porém nos Estados Unidos, tem um Committee on Women Historians - Comitê de Mulheres Historiadoras ${ }^{15}$. Estas, publicaram, em 2005, o "Estatuto da Mulher Historiadora", no qual falam dos importantes ganhos das mulheres historiadoras em décadas recentes, bem como das restrições que ainda permanecem e que as inibem de alcançar seu pleno potencial, dentro da academia, pois as desigualdades persistem.

\footnotetext{
${ }^{14}$ Ver: FINCO, Daniela, GOBBI, Marcia Aparecida e FARIA, Ana Lúcia Goulart de (org.). Creche e feminismo: desafios atuais para uma educação descolonizadora. Campinas, SP: Edições Leitura Crítica; Associação de Leitura do Brasil - ALB; São Paulo: Fundação Carlos Chagas FCC, 2015.

15 Ver: AMERICAN Historical Association. Committee on Women Historian' 1980 Summary Report. Disponível em: https://www.historians.org/about-aha-and-membership/aha-history-andarchives/historical-archives/committee-on-women-historians-1980-summary-report. Acesso em 30 maio 2020.
} 
Dossiê: Ensino de História, História das Mulheres e Desigualdades Sociais no Brasil

Recomendam, então, às pessoas que ocupam a gestão das universidades, tais como, chefias de departamento, reitorias, enfim administração, que têm a possibilidade de ajudar a modificar a cultura e as práticas institucionais, a tornálas mais igualitárias. Fazem, então, várias recomendações, das quais destacarei algumas:

1. Não fiquem esperando que as mulheres reclamem, tomem a iniciativa de tornar o ambiente mais inclusivo.

2. Garantam que o local de trabalho esteja livre de linguagem e de conduta preconceituosa.

3. Combatam o assédio e a discriminação baseada na orientação sexual.

4. Assegurem que todas terão o mesmo tipo de tratamento, não chamem os homens de professor, doutor e as mulheres como senhora, senhorita ou pelo primeiro nome, desconhecendo seus títulos.

5. Assegurem que as professoras com mais tempo na instituição orientem as novas professoras sobre as possibilidades de pesquisa e os meios de subir na carreira universitária, disponibilizando as formas de obter os benefícios disponíveis.

6. Facilitem o contato com as organizações de conferências, editorias de revistas e editoras para fornecer locais para a divulgação de trabalhos acadêmicos para todas.

7. Garantam a equidade de gênero nas avaliações, reconhecendo o impacto do gênero em percepções e avaliações de mulheres na pesquisa, no ensino e na extensão, por exemplo: uma mulher que costuma ser mais rigorosa em suas exigências como professora, é considerada uma "senhora desagradável", enquanto que um professor será visto, na avaliação pelos estudantes, como um professor brilhante. Além disso, colegas podem rotular as mulheres como "difíceis" quando são assertivas e o mesmo comportamento, nos homens, passará despercebido. As mulheres relatam que elas têm que trabalhar mais, para serem vistas como competentes, por alunos e colegas.

8. Garantam que o objeto de investigação não será alvo de desprezo. Pesquisadoras relatam que quando alguém trabalha com história das mulheres, do gênero ou da sexualidade, sua pesquisa sofre 


\section{HISTÓRIA}

Dossiê: Ensino de História, História das Mulheres e Desigualdades Sociais no Brasil desconsideração. Por outro lado, não esperem que elas só pesquisem este assunto.

9. Assegurem equidade de gênero na atribuição de funções acadêmicas, recomendem mulheres para os comitês institucionais de formulação de políticas de prestígio, não apenas aqueles relacionados a gênero ou raça.

10. Distribuam, também, igualmente, as funções que não trazem prestígio, por exemplo, secretariar reuniões.

11. Distribuam os recursos como: espaço de escritório, equipamentos, instalações e apoio de secretariado e de pessoal, de forma igualitária.

Uma destas recomendações me pareceu muito importante: "entender que a vida acadêmica precisa levar em conta a vida familiar". Para tanto, recomendam que o relógio biológico não seja desconsiderado - este incide principalmente sobre as mulheres. Neste caso, a Associação de Mulheres Historiadoras recomenda: carga de trabalho flexível e reduzida, creches, serviços de cuidados com idosos e doentes, fazer reuniões compatíveis com a vida familiar, reconhecer que o cumprimento das obrigações familiares não significa descompromisso profissional, garantir que as obrigações profissionais não sejam incompatíveis com as exigências familiares. Permitir que as jovens mães interrompam ou reduzam a produção, em suas carreiras, sem que isso lhes prejudique o prestígio e o futuro.

Note que estas recomendações, certamente, não deveriam ser limitadas às historiadoras, mas a todas as pesquisadoras, de qualquer área do conhecimento. Ainda não vi, no Brasil, estas recomendações sendo levadas para as universidades e órgãos financiadores. Penso que os novos grupos, formados por jovens feministas, deveriam incorporar estas pautas.

Entrevistadoras: - Como a historiografia brasileira pode incluir a problemática de gênero vinculada à intersecção entre raça e classe social, em particular, dando visibilidade à atuação das mulheres negras e pobres?

Joana Maria Pedro: - Penso que algumas pesquisadoras já fazem isso há algum tempo, sem chamar de intersecção. Maria Odila Leite da Silva Dias, por 
Dossiê: Ensino de História, História das Mulheres e Desigualdades Sociais no Brasil

exemplo, no livro "Cotidiano e Poder"16, descreve a vida de mulheres pobres, muitas delas negras, na cidade de São Paulo, na década de 30 do século XIX. Eu mesma, no livro "Mulheres Honestas e Mulheres Faladas uma questão de classe" 17 , resultado de minha tese de doutorado e publicado em 1994, articulei na narrativa gênero, classe e raça, mas não usei a categoria "interseccionalidade". Eu poderia citar vários outros trabalhos que fizeram isso, sem usar a categoria. Mas é claro que a palavra "interseccionalidade" ajuda a refletir; como já mencionei, é bom darmos nomes àquilo que refletimos. Esta categoria é oriunda do feminismo negro norte-americano, e tem sido cada vez mais utilizada. Quando Kimberle Crenshaw apresentou a categoria, no "Documento para o encontro de especialistas em aspectos da discriminação racial relativos ao gênero"18, esta não era desconhecida. Ao dar nome ao impacto diferenciado sobre as pessoas das discriminações de gênero, raça e classe, a autora apresentou uma categoria que permitiria pensar estes cruzamentos. Outras autoras ${ }^{19}$ têm discutido a interseccionalidade e esta categoria, cada dia mais, tem sido considerada como imprescindível nas reflexões da área de ciências humanas. Há, ainda, autoras questionando esta categoria e definindo que, em alguns contextos, a questão da raça é mais importante que gênero e classe. ${ }^{20}$ Enfim, não falta bibliografia e discussões que apoiem qualquer pessoa que pesquisa, para usar a categoria. Afinal é necessário, cada vez mais, levar em conta, por meio da na narrativa histórica, as múltiplas questões que a atravessam.

\footnotetext{
${ }^{16}$ DIAS, Maria Odila Leite da Silva. Quotidiano e Poder em São Paulo no século XIX. São Paulo: Brasiliense, 1984.

${ }^{17}$ PEDRO, Joana Maria. Mulheres honesta e mulheres faladas uma questão de classe. Florianópolis: Editora da UFSC, 1994.

${ }^{18} \mathrm{CRENSHAW}, \mathrm{KIMBERLÉ}$. Documento para o encontro de especialistas em aspectos da discriminação racial relativos ao gênero. Revista Estudos Feministas [online]. 2002, vol.10, n.1 pp.171-188. Disponível em: <http://www.scielo.br/scielo.php?script=sci_arttext\&pid=S0104026X2002000100011\&lng=en\&nrm=iso>. Acesso em 27 maio 2020.

19Ver: PLATERO, Raquel (Lucas). (Ed.) Intersecciones: cuerpos y sexualidades en la encrucijada. Barcelona: EdicionsBellaterra, S.L., 2012; AKOTIRENE, Carla. O que é interseccionalidade? Belo Horizonte: Letramento: Justificando, 2018.

${ }^{20}$ Ver a este respeito: BOUTELDJA, Houria. Raça, Classe e Gênero: uma nova divindade de três cabeças. Cadernos de Gênero e Diversidade, Salvador, v. 2, n. 2, p.5-9, dez. 2016. Disponível em: <https://portalseer.ufba.br/index.php/cadgendiv/article/view/20686/13991>. Acesso em 27 maio de 2020.
} 
Dossiê: Ensino de História, História das Mulheres e Desigualdades Sociais no Brasil

Entrevistadoras: - Em tempos de pandemia de Covid-19, a maioria das mulheres tem lugar central nas estatísticas de mortandade e, em particular, as negras, que atuam no trabalho informal, que moram nas periferias - sem água potável e sem saneamento básico - e que não contam com cônjuges na criação dos filhos. Quais medidas de equidades de gênero e políticas públicas poderiam ser implementadas para que pudessem alcançá-las de forma urgente e eficaz, além da renda emergencial do governo, fortalecendo as redes de segurança e cuidados com a saúde de mulheres e a educação?

Joana Maria Pedro: - Os dados têm mostrado que tem morrido mais homens que mulheres, chego a pensar que elas se cuidam mais, elas usam máscara. $\mathrm{Na}$ rua, vejo mais homens sem máscaras que mulheres. Além disso, os homens acumulam mais problemas de saúde como diabetes, cardiopatias, pressão alta e são resistentes a comparecer a médicos e exames, que poderiam sanar alguns destes problemas. E, como sabemos, este vírus não é democrático, impacta de forma desigual por classe, raça e gênero. Assim, impacta, promove alto número de contágio, mas, não necessariamente, levam à morte muitas mulheres negras, pobres, que precisam trabalhar, que lidam com crianças, que, neste momento, não estão na creche ou na escola. Estas crianças vivem em moradias pequenas, não têm como mantê-las dentro de casa e, o que se vê é o contágio que elas levam para dentro de casa, mesmo de maneira assintomática. Terminam por fazer adoecer as mães e as avós. Muitas vezes, estas avós têm aposentadoria, única receita garantida da família.

O que se vê, e com resultados desastrosos, são mulheres enfermeiras e auxiliares de limpeza nos hospitais e clínicas, a grande parte não-brancas, morrendo por causa do corona-vírus. O Brasil é o país que tem mais morte do pessoal de enfermagem. Até o dia 26.05, já haviam falecido 157 pessoas da enfermagem. Em segundo lugar, estava os Estados Unidos, com 146 óbitos e 77 no Reino Unido. ${ }^{21}$

Creio que uma política pública deveria ser implementada para tornar a "renda emergencial" (que é muito baixa) um auxílio permanente, que estivesse mais

${ }^{21}$ DANTAS, Carolina. Brasil é o país com mais mortes de enfermeiros por Covid-19 no mundo, diz entidades. G1. 27 maio de 2020.2 Disponível em: https://g1.globo.com/bemestar/coronavirus/noticia/2020/05/27/brasil-e-o-pais-com-mais-mortesde-enfermeiros-por-covid-19-no-mundo-dizem-entidades.ghtml. Acesso em: 27 maio 2020. 


\section{HISTÓRIA}

Dossiê: Ensino de História, História das Mulheres e Desigualdades Sociais no Brasil condizente com a realidade, ou seja, a criação de uma "renda mínima" para todas as pessoas que garantissem um mínimo de dignidade, além de saúde e educação pública e gratuita em todos os níveis. Isto seria a garantia de condições dignas e de cidadania. Além disso, uma infraestrutura sanitária daria condições de saúde para estas pessoas.

O que a pandemia veio mostrar foi a extrema desigualdade, e eu entendo que é isto que precisa desaparecer. Taxar as grandes fortunas e as igrejas, certamente traria renda para implementar políticas que reduzissem estas desigualdades tão extremas.

\section{Eixo 3: Os ensinos de História promovendo equidade de gênero}

Entrevistadoras: - A agenda neoconservadora religiosa e moral no Brasil aproxima-se cada vez mais de um projeto de educação neoliberal e voltado para a finalidade única de atendimento e formação de mercados. Nesse contexto, os estudos de gênero tiveram suas características e objetivos distorcidos por discursos públicos, que tinham como interesse a promoção de um pânico moral em consonância com a política conservadora. Como o ensino de História, dentro da perspectiva de gênero, especialmente o oferecido pelos(as) professores(as) da educação básica, pode ser utilizado em resposta a esse ataque? No âmbito das formações acadêmicas em licenciaturas, qual sua compreensão acerca da inclusão de estudos feministas e de gênero como componente curricular obrigatório?

Joana Maria Pedro: - O ensino de História com abordagem de gênero serve, antes de mais nada, para destruir este discurso que atribui à natureza e a Deus a obrigatoriedade da heterossexualidade e as hierarquias de gênero. $A$ atribuição a Deus da existência de diferenças imensas entre homens e mulheres, definindo para cada um atribuições, caráter e capacidades tão diversas, e, ainda a obrigatoriedade da heterossexualidade, considerando qualquer forma de dissidência como um pecado - resultado do conservadorismo, do crescimento da direita -, tem trazido um grande prejuízo na forma de preconceito, discriminação e violência. 
Dossiê: Ensino de História, História das Mulheres e Desigualdades Sociais no Brasil

Outro lado deste discurso é o uso da natureza. Costumam dizer que "a natureza fez homem e mulher diferentes para procriar". É semelhante ao discurso religioso fundamentalista, apenas usa a "natureza". Com certeza não estudam biologia, não estudam a natureza. Se estudassem, saberiam que a "natureza" é bem mais complexa, que o considerado masculino ou feminino não se resume a parâmetros focados na genitália e nem nos cromossomos. Um trabalho, de 2005, da Cadernos Pagu, já antigo, e que eu gosto muito de citar, é o "Sexo dos Anjos", de autoria de Paula Sandrine Machado22. Ela mostra que 1 em 2000 crianças nascem com genitália ambígua ${ }^{23}$, são chamadas de intersexo. Há, ainda, a questão do $X X$ e $Y$, cromossomos que costumam ser utilizados para designar o masculino e o feminino e cuja variedade é de intensa complexidade, impedindo a identificação. Tudo isso a própria biologia mostra, e a história pode apontar a existência e pessoas intersexo, pessoas homossexuais, a complexidade da sexualidade, a presença de mulheres exercendo funções que a relação de gênero vigente não aceitava, em diferentes momentos da história. Dar historicidade à própria noção de sexualidade, mostrar a invenção da "mulher" como sexo frágil, ajuda a ampliar a noção de cidadania.

Entrevistadoras: - A senhora afirmaria que a esquerda política vem trabalhando de forma mais focada que a direita, no Brasil, no que concerne à equidade de gênero, em particular, no que tange aos direitos das mulheres e das minorias sexuais? Em especial, qual sua avaliação da formação em Gênero e Diversidade na Escola, ofertada pela SECADI/MEC nos governos PT?

Uma parcela da direita, no Brasil tem se apoiado no "pânico moral"24, criando pela ideia de "Ideologia de gênero" para destruir políticas que buscaram a igualdade de gênero e que foram implementadas nos governos do PT. Posso citar algumas destas iniciativas que divulgaram as discussões de gênero e sexualidade e que deram legitimidade a estas discussões: 1) no início do século

\footnotetext{
${ }^{22}$ MACHADO, Paula Sandrine. O sexo dos anjos: um olhar sobre a anatomia e a produção do sexo (como se fosse) natural. Cadernos Pagu.(24), janeiro-junho de 2005, pp. 249-281. Disponível em: http://www.scielo.br/scielo.php?script=sci arttext\&pid=S010483332005000100012\&lng=en\&nrm=iso. Acesso em: 24 maio 2020.

${ }^{23}$ Genitália ambígua, ou seja, não é possível reconhecer como masculina ou feminina.

${ }^{24}$ Sobre o pânico moral e a Ideologia de gênero ver: MISKOLCI, Richard \& CAMPANA, Maximiliano Campana . "Ideologia de gênero": notas para a genealogia de um pânico moral contemporâneo. Revista Sociedade e Estado - Volume 32, Número 3, Setembro/Dezembro 2017. p.725-744. Disponível em: <http://www.scielo.br/scielo.php?script=sci_arttext\&pid=S010269922017000300725\&Ing=en\&nrm=iso>. Acesso em: 24 jun. 2020.
} 
Dossiê: Ensino de História, História das Mulheres e Desigualdades Sociais no Brasil

XXI, os concursos realizados pela SPM - Secretaria de Políticas Públicas para Mulheres, junto com o CNPq - Conselho Nacional de Pesquisa, abriram editais com recursos para pesquisa em gênero e sexualidade; 2) os concursos de redação, e artigos científicos intitulados "Construindo a Igualdade de Gênero", voltados para estudantes de ensino médio, graduação e pós-graduação, também organizados pela SPM ${ }^{25}$. Inúmeros estudantes, de todo o Brasil, participaram, mostrando que estes conhecimentos estavam chegando a diferentes lugares do país; 4) as atuações da SECADI - Secretaria de Educação Continuada, Alfabetização, Diversidade e Inclusão, que apoiou cursos de Gênero e Diversidade na Escola, formando especialistas e criando uma grande rede de conhecimento que fortaleceram as pesquisas sobre o feminismo, História das Mulheres, relações de gênero e sexualidades.

Estes foram projetos desenvolvidos pela esquerda, que, no momento em que vivemos, com a extrema direita no poder, estão sendo destruídos, infelizmente.

Entrevistadoras: - Agradecendo seu trabalho de toda uma vida e a gentileza em nos conceder essa entrevista, gostaríamos de conhecer algumas sugestões, dicas, conselhos, seus para professoras(es) de História iniciantes na carreira, e também para aquelas(es) que, nos diferentes espaços de formação, atuam com o conhecimento histórico acerca de história das mulheres, relações de gênero e feminismos.

Joana Maria Pedro: - A história das mulheres, das relações de gênero e dos feminismos estão, neste momento, sob ataque. Há uma disputa discursiva muito séria. Porém não podemos desanimar. Notamos que depois que começou esta discussão sobre "Ideologia de Gênero", mais pessoas se interessaram em saber o que é "gênero". Nossos eventos têm sido lotados, as aulas sobre estas temáticas são cada vez mais concorridas. A decisão do STF - Supremo Tribunal Federal, declarou inconstitucional a lei municipal de "Ideologia de Gênero, em

\footnotetext{
${ }^{25}$ O Prêmio Construindo a Igualdade de Gênero foi instituído em 2005 pela Secretaria de Política das Mulheres (SPM-PR), no âmbito do Programa Mulher e Ciência, em parceria com o Conselho Nacional de Desenvolvimento Científico e Tecnológico (CNPq/MCTI); a Secretaria de Educação Continuada, Alfabetização e Diversidade (SECADI/MEC); a Secretaria de Educação Básica (SEB/MEC) e a ONU Mulheres. Ver: ONU Mulheres BR. Prêmio Construindo a Igualdade de Gênero está com inscrições abertas até 28/11. Disponível em: http://www.onumulheres.org.br/noticias/premio-construindo-a-igualdade-de-genero-esta-cominscricoes-abertas/ acesso em 24.06.2019.
} 


\section{HISTÓRIA}

Dossiê: Ensino de História, História das Mulheres e Desigualdades Sociais no Brasil

24.04.202026; significou um grande alívio, mas, certamente não resolveu, ainda, esta questão. O atual presidente garantiu que enviará ao Congresso Nacional um "projeto constitucional", para proibir "Ideologia de Gênero" na escola ${ }^{27}$. Isto significa que precisaremos continuar atentas.

Uma outra questão que eu queria abordar, para finalizar, é lembrar que, neste momento, a disciplina História precisa ser acessada pelo público mais amplo, usando diferentes meios de divulgação e não somente o artigo científico ou o livro acadêmico. A "História Pública" tem buscado fazer isso; entretanto, os negacionistas têm se apropriado, ao seu modo, de conteúdos históricos e contando com muitos recursos financeiros, detêm meios de divulgação de melhor qualidade. O que estou sugerindo é que, ao lado da pesquisa séria embasada em fontes, que devemos continuar a fazer, precisamos, também, investir em modalidades cada vez mais populares de divulgação do conhecimento histórico. Não basta gravar um vídeo ou fazer um podcast cheio de informações importantes; estas devem ser apresentadas de maneira que atraia a atenção, e que induza as pessoas desejarem conhecer história. Precisamos aprender os melhores caminhos para disputar este campo.

${ }^{26}$ SALDAÑA, Paulo. Por unanimidade, Supremo declara inconstituicional lei municipal de ‘ideologia de gênero'. Folha de S. Paulo (Digital). 24 abr. 2020. https://www1.folha.uol.com.br/educacao/2020/04/stf-forma-maioria-para-declararinconstitucional-lei-que-veta-discussao-de-genero-nas-escolas.shtml. Acesso em: 31 maio 2020. ${ }^{27}$ BEHNKE, Emilly. Bolsonaro promete projeto sobre ideologia de gênero. 12 maio 2020. Disponível em: https://www.terra.com.br/noticias/brasil/politica/bolsonaro-promete-projetosobre-ideologia-de-genero,e8ddf73b3d2a8e2abd738bdaabb17fc7g11llbk44.html. Acesso em: 31 maio 2020. 